\title{
A COBERTURA JORNALÍSTICA NO PERÍODO ELEITORAL Uma análise a partir das eleições 2008 no interior do Paraná
}

\section{THE COVERAGE DURING THE ELECTION PERIOD: AN ANALYSIS FROM THE 2008 ELECTIONS IN THE INTERIOR OF PARANÁ}

\author{
Ana Paula Hedler ${ }^{1}$, Sérgio Luiz Gadini ${ }^{2}$ e Emerson Urizzi Cervi ${ }^{3}$
}

\section{RESUMO}

O artigo analisa como os jornais Diário do Norte, Folha de Londrina, Diário dos Campos, Jornal da Manhã e Gazeta do Povo veicularam suas notícias durante o período eleitoral de 2008. 0 texto é resultado parcial de uma pesquisa mais ampla realizada pelo Grupo de Pesquisa "Mídia, Política e Atores Sociais", da Universidade Estadual de Ponta Grossa. A metodologia utilizada pelo grupo é a Análise de Conteúdo, com variações de enfoque quantitativo e qualitativo. A fim de atingir os objetivos, foram considerados os temas que mais apareceram na cobertura jornalística, o enquadramento dado às reportagens, o número de fontes utilizadas para a produção da notícia e outros aspectos editoriais, como tamanho e localização na página.

Palavras-chave: Jornalismo político. Período eleitoral. Cobertura jornalística paranaense. Eleições. Agenda-setting.

\footnotetext{
1 Jornalista e mestranda em Ciência Política pela Universidade Federal do Paraná (UFPR), e-mail para contato: ana_hedler@hotmail.com.

2 Doutor em Ciências da Comunicação pela Universidade do Vale do Rio dos Sinos e professor adjunto de Comunicação Social - Jornalismo, da Universidade Estadual de Ponta Grossa (UEPG/PR), e-mail para contato: sergiogadini@yahoo.com.br.

3 Doutor em Ciência Política pelo Instituto Universitário de Pesquisas do Rio de Janeiro, professor do Departamento de Comunicação Social da Universidade Estadual de Ponta Grossa (UEPG/PR) e professor do Departamento de Ciências Sociais da Universidade Federal do Paraná (UFPR), e-mail para contato: ecervi7@gmail.com.
} 


\begin{abstract}
The paper analyzes how the newspapers Diário do Norte, Folha de Londrina, Diário dos Campos, Jornal da Manhã and Gazeta do Povo divulged his news about the electoral period of 2008. The text is partial's results of a broader research carried out by the research's groups in "Mídia, Política e Atores Sociais", of the Universidade Estadual de Ponta Grossa and "Comunicação Política e Opinião Pública" of the Universidade Federal do Paraná. The methodology utilized by the group is analysis of content, with variations of qualitative and quantitative approach. In order to reach the objectives, it were considered the subjects that more appeared in the journalistic cover, the frame given to the reportings, the number of people that were interviewed and others editorial aspects as size and location in the page.
\end{abstract}

Keys-words: Political Journalism. Electoral Period. Paranás Journalistic Cover. Elections. Agenda-Setting.

\title{
INTRODUÇÃO
}

Este trabalho tem por objetivo analisar comparativamente a cobertura jornalística sobre disputas para prefeituras municipais realizada por cinco jornais paranaenses durante o período eleitoral de 2008. Para tanto, foram estudados os jornais Gazeta do Povo, Folha de Londrina, Diário do Norte, Diário dos Campos e Jornal da Manhã, respectivamente localizados nos municípios de Curitiba - capital do Estado -, Londrina, Maringá e os dois últimos, em Ponta Grossa. 0 período da análise compreende os meses de agosto, setembro e outubro de 2008 - durante o período oficial das campanhas eleitorais.

A análise do período eleitoral é importante, pois se faz necessário saber o que os meios de comunicação de massa estão colocando em debate na esfera pública. Isso porque, a partir dos temas que a mídia aborda, o público pode vir a discutir certos assuntos e ao mesmo tempo silenciar outros com grande relevância social (MCCOMBS E SHAW, 1972). Entende-se que a cobertura do período eleitoral tende a apresentar os candidatos envolvidos nas disputas pelo poder, suas propostas bem como os pontos que necessitam de atenção dos políticos para a melhoria do bem-estar dos eleitores, como, por exemplo, a implantação de políticas públicas. Nesse sentido, se houver predomínio de determinado tema na cobertura, maior presença comparativa de determinado candidato ou predominância de determinada valência a respeito dos candidatos, isso pode interferir na formatação do debate público a respeito do tema.

$\mathrm{O}$ artigo divide-se em três partes. Na primeira, faz-se uma breve introdução aos conceitos e teorias utilizadas para embasar a pesquisa. No segundo item, estão os resultados da pesquisa ou observações correspondentes aos mesmos e, para finalizar, apresentam-se as considerações finais sobre os resultados.

\section{DEBATE TEÓRICO SOBRE OS CRITÉRIOS DE NOTICIABILIDADE POLÍTICA}

Desde o surgimento dos meios de comunicação modernos, no século XVII, pode-se dizer que há o problema da necessidade de escolha dos assuntos que serão notícias em detrimento daqueles que não serão. Tal prática aumentou quando modernizaram-se as empresas jornalísticas e o número de informações disponíveis (KUNCZIK, 2002). Para sanar essa dificuldade, aos poucos, a mídia foi forjando critérios de noticiabilidade, que têm a função de auxiliar os repórteres e editores a escolher e diferenciar o que é realmente notícia dos temas que ficam apenas na agenda privada das pessoas.

Os critérios de noticiabilidade definem a aptidão de cada acontecimento para se tornar notícia, pois, como se sabe, há restrições ligadas à organização do trabalho jornalístico (WOLF, 
2006). Assim, para que um fato venha a ser notícia é preciso que ele se encaixe nos padrões estabelecidos, de tal modo que quando não se enquadra nas rotinas de produção e nos cânones da cultura profissional ele é excluído.

Pode também dizer-se que a noticiabilidade corresponde ao conjunto de critérios, operações e instrumentos com os quais os órgãos de informação enfrentam a tarefa de escolher, cotidianamente, entre um número imprevisível e indefinido de fatos, uma quantidade finita e tendencialmente estável de notícias (WOLF, 2006, p. 190).

Como é, de fato, através dos meios de comunicação que grande parte da população se mantém informada, é necessário observar o que os jornais consideram como relevante para se divulgar. Isso porque a mídia pode pautar os debates gerados na sociedade a partir do momento em que coloca certos temas em suas páginas, na programação televisiva, no rádio ou na internet (McCOMBS, 1997).

McCombs e Shaw (1997) acreditam que, a médio e longo prazo, os meios de comunicação ajudam a estruturar a imagem da realidade social, além de organizar os elementos dessa mesma imagem e a formar novas opiniões e crenças. McCombs acredita que a "noção básica, primitiva de agendamento é um truísmo", porque caso os meios de comunicação não informem ao público sobre os diversos temas e tópicos de um acontecimento, eles dificilmente existirão na esfera pública ${ }^{4}$, tendendo assim, a permanecerem apenas na agenda pessoal dos envolvidos diretamente com o assunto (apud TRAQUINA, 2001, p. 22).

De maneira complementar à hipótese do agendamento está a teoria da espiral do silêncio proposta pela socióloga Elisabeth Noëlle-Neumann, em 1973. Para a autora, quando a pessoa encontra-se em situação de instabilidade e precisa tomar partido para defender sua opinião, se seu ponto de vista está de acordo com a opinião dominante e tende a ser mais fácil se manifestar, caso contrário a tendência é que haja um silenciamento da opinião, pois percebendo que seu ponto de vista não é majoritário a pessoa fica menos segura e menos propensa a se expressar (NOËLLE-NEUMANN, 1995). Para Sousa (2002), isso faz com que as pessoas se mantenham atentas às opiniões e aos comportamentos dominantes, procurando se expressar dentro do padrão da suposta maioria, por isso, além de observar quais são os temas que ganham atenção dos meios de comunicação de massa, é necessário atentar para a forma como a mídia os trata. Em se tratando de debate eleitoral, a importância em se dar visibilidade ao tema cresce, pois será desse debate que surgirão forças políticas representativas predominantes, identificadas com determinadas posições e propostas relativas aos assuntos que foram debatidos.

Para Mauro Porto (2000), é necessário analisar como a mídia traz os assuntos à tona, porque existem diferentes meios de se retratar o mesmo acontecimento e isso influenciará a maneira como o receptor assimilará a notícia. Para ele, com base na literatura internacional sobre o tema, existem quatro tipos diferentes de enquadramentos nos quais pode-se encaixar o formato das reportagens. São eles: corrida de cavalos, personalista, temático e episódico. Cada enquadramento proposto indica como o repórter seleciona, hierarquiza e trata os elementos que deverão fazer parte da sua matéria. Enquanto a primeira classificação diz respeito às repor-

\footnotetext{
4 Usamos aqui a definição que Habermas (2003) dá para o conceito de esfera pública. Para o autor, esfera pública designa o espaço no qual interesses, vontades e pretensões, que dizem respeito a uma coletividade, são colocados em discussão e onde pessoas privadas se utilizam da lógica da argumentação para discutirem reunidas num público.
} 
tagens que mostram avanços e retrocessos das pesquisas de opinião sobre a campanha eleitoral, a segunda faz um perfil detalhado de uma personagem, geralmente candidato ao cargo político disputado. O temático, por sua vez, é o que mais interessa à pesquisa de cobertura jornalística, porque são as reportagens que se baseiam nas pesquisas, na interpretação de um conjunto de dados e documentos. E, por fim, o episódico indica uma descrição editorial detalhada, mostrando o que acontece, sem interpretar o assunto.

Como no jornalismo nenhum assunto é publicado de forma aleatória, nas páginas dos jornais, além de observar os temas mais recorrentes e como eles são tratados pelos repórteres, faz-se necessário pesquisar o local no qual estão inseridas certas temáticas e o espaço que as mesmas ocupam. Afinal, uma notícia que é considerada manchete do dia tem peso maior do que outra que se torna uma breve nota jornalística. Para Amaral (1978, p. 68), "cada lugar na página tem um valor específico ligado à maior ou menor facilidade com que o leitor chega à matéria". Sendo que "a primeira metade do jornal é mais importante do que a segunda, o lado direito mais do que o esquerdo, o lado superior esquerdo mais do o centro". Os jornais apresentam diferentes tipos de diagramação, o que demonstra que a disposição da matéria é importante para a empresa e não é algo feito ao acaso, muito pelo contrário, a diagramação das páginas dos jornais é pensada para que sempre a informação seja privilegiada, haja legibilidade do conteúdo, beleza e estilo. O local que a notícia ocupa na página está relacionado a menor ou maior facilidade com que o leitor tem acesso à notícia. (AMARAL, 1978).

Assim, para observar todos os componentes editoriais do jornal, esta pesquisa utiliza a metodologia de análise de conteúdo, buscando destacar aspectos quantitativos e qualitativos. Para Galera e Conde (2005, p. 30, tradução nossa), a "perspectiva quantitativa engloba uma série de técnicas de investigação que pretende obter e medir dados sobre a realidade social" ${ }^{5} \mathrm{e}$, dessa forma, seu enfoque é mais explicativo. Já "o método qualitativo integra uma informação sobre os fenômenos sociais mais rica e profunda que aquela que se pode obter com a técnica quantitativa" ${ }^{\prime}$, assim a análise qualitativa é mais interpretativa e subjetiva (GALERA; CONDE, 2005, p. 31). Considera-se análise quantitativa, por exemplo, o número das entradas jornalísticas. Já a análise qualitativa refere-se à classificação dos formatos e à visibilidade dos temas.

O levantamento de dados empíricos englobou o período de primeiro de agosto até 31 de outubro de 2008, por se tratar do período de campanha eleitoral para prefeitos e vereadores. Foram escolhidos para o estudo os jornais Diário do Norte, Folha de Londrina, Diário dos Campos, Jornal da Manhã e Gazeta do Povo. A opção por estes impressos justifica-se porque os quatro primeiros jornais são editados nas três cidades do interior do Paraná com mais de 200 mil eleitores (Maringá, Londrina e Ponta Grossa), portanto com possibilidade de contar com segundo turno de disputa para escolha do prefeito, além do fato de a Gazeta do Povo ser o jornal de maior veiculação na capital do Estado, Curitiba.

O impresso Diário dos Campos circula em Ponta Grossa e região dos Campos Gerais do Paraná. Foi fundado por Jacob Holzman sob o título de "O Progresso", em 1907. Atualmente circula de terça a domingo, com uma média de cinco mil exemplares em dias de semana e com 10 mil exemplares na edição dominical. Já seu concorrente local em Ponta Grossa, o Jornal da Manhã, passou (em 2007) por uma ampla reforma gráfico/editorial e foi fundado em 1954. O JM conta com sete cadernos especiais e integra o "Grupo Tribuna de Comunicação". A Folha de

\footnotetext{
5 "La perspectiva cuantitativa engloba uma serie de técnicas de investigación que pretende obtener y medir datos sobre la realidad social" (GALERA; CONDE, 2005, p. 30, tradução nossa).

6 "El método cualitativo aporta uma información sobre los fenómenos sociales más rica y profunda que la que se puede obtener mediante técnicas cuantitativas" (GALERA; CONDE, 2005, p. 31).
} 
Londrina é um jornal de circulação local, na maior cidade do interior do Estado (Londrina), conta com nove cadernos e circula todos os dias da semana, mantendo uma sucursal em Curitiba. Já o Diário do Norte faz parte do grupo de comunicação "O Diário", que conta com a rádio Cultura AM, Dflash, e Diário Online. Mesmo com variações, a estimativa de circulação do $D C$ não foge muito à realidade do $J M$ e $D N$. A Folha de Londrina, por sua vez, registra uma tiragem um pouco superior (estimada em 20 exemplares ao dia).

É oportuno considerar que a escolha pela análise de dois jornais diários de Ponta Grossa ( $D C$ e $J M)$, diferente das outras duas cidades, deve-se ao fato de que, em Ponta Grossa, existem periódicos com influência de leitura/alcance de proporções muito similares. Tal situação não acontece em Londrina e Maringá, onde os jornais que integram a amostragem deste estudo (FL e $D N)$ possuem uma hegemonia no mercado de mídia impressa diária.

Já a Gazeta do Povo existe desde 1919 quando Benjamim Lins fundou o periódico em Curitiba. Atualmente, é considerado o maior jornal do estado do Paraná em tiragem e tem circulação regional. Faz parte do Grupo RPC (Rede Paranaense de Comunicação) juntamente com o Jornal de Londrina, Portal RPC, 98 FM e RPC TV. Seu formato é standard, periodicidade diária e é composto por quatro cadernos.

Levando em consideração que os meios de comunicação têm o poder de pautar os assuntos que serão debatidos na esfera pública e que podem também não abordar outros, o que acaba silenciando a discussão de temáticas de potencial interesse e relevância social, a seção seguinte traz a análise dos resultados obtidos nos três meses da cobertura jornalística do período eleitoral de 2008.

\section{RESULTADOS E OBSERVAÇÕES POSSÍVEIS}

O período da coleta de dados foi de três meses, no qual foram coletadas 1918 entradas jornalísticas, ou seja, textos informativos ou opinativos que incluíam o nome de pelo menos um candidato. $\mathrm{O}$ estudo computou matérias, notas, reportagens, fotografias, charges e outros formatos (jornalísticos) nos quais estavam presentes um ou mais candidatos a prefeito nos municípios de Londrina, Maringá, Ponta Grossa e Curitiba.

Como critérios de classificação, foram selecionados os temas gerais das notícias, os temas específicos, o espaço que as matérias ocuparam na página, o número da página nas quais estavam presentes, se foi utilizado o recurso fotográfico ou não, o enquadramento das reportagens, a utilização de fontes de informação, a origem das mesmas e a presença dos líderes políticos regionais nas matérias.

A primeira tabela traz o formato das entradas jornalísticas. Nota-se que $41,23 \%$ do total de entradas coletadas foram reportagens, o que demonstra preocupação dos repórteres em aprofundar as notícias, procurando fazer questionamento daquilo que se está reportando, sendo que muitas vezes há interpretação de dados e a pesquisa é essencial. Entre os cinco jornais apenas o Diário dos Campos e Gazeta do Povo não utilizaram a reportagem como formato predominante. $O$ formato que predominou em ambos foi Coluna Assinada. 
Tabela 1 - Formato jornalístico das notícias

\begin{tabular}{|l|l|l|l|l|l|l|l|l|}
\hline Indicadores & $\begin{array}{l}\text { Chamada } \\
\text { primeira } \\
\text { página }\end{array}$ & Reportagem & $\begin{array}{l}\text { Charge } \\
\text { Infográfico } \\
\text { Ilustração }\end{array}$ & Foto & $\begin{array}{l}\text { Coluna } \\
\text { assinada }\end{array}$ & $\begin{array}{l}\text { Artigo } \\
\text { assinado }\end{array}$ & Editorial & Total \\
\hline Diário do Norte & 10 & 74 & 3 & 10 & 42 & 20 & 1 & 160 \\
\hline $\begin{array}{l}\text { Folha de } \\
\text { Londrina }\end{array}$ & 3 & 105 & 0 & 2 & 31 & 0 & 3 & 144 \\
\hline $\begin{array}{l}\text { Diário dos } \\
\text { Campos }\end{array}$ & 39 & 161 & 20 & 30 & 187 & 0 & 8 & 445 \\
\hline $\begin{array}{l}\text { Jornal da } \\
\text { Manhã }\end{array}$ & 32 & 208 & 75 & 36 & 104 & 9 & 24 & 488 \\
\hline Gazeta do Povo & 26 & 242 & 57 & 100 & 248 & 6 & 0 & 679 \\
\hline Total & 110 & 790 & 155 & 178 & 612 & 35 & 36 & 1916 \\
\hline
\end{tabular}

Fonte: Grupo de Pesquisa “Mídia, Política e Atores Sociais” (UEPG).

O Diário do Norte, a Folha de Londrina e o Jornal da Manhã escolheram as reportagens como principais formatos, pois as porcentagens foram de $46,25 \%, 72,91 \%$ e $42,62 \%$, respectivamente. Já para o Diário dos Campos a percentagem foi de 36,17\%, e na Gazeta do Povo, 35,64\%. $\mathrm{O}$ uso da Coluna Assinada indica que os jornais priorizam a interpretação do colunista à produção de reportagens, porque ela é o espaço destinado a algum jornalista especializado, sobre algum tema específico, como política e economia, por exemplo. $\mathrm{O}$ autor é mais importante que o assunto que está sendo tratado, é quem assina o material e tem suas fontes de informação próprias.

No geral, o formato que menos apareceu foi Artigo Assinado, com 1,82\% da cobertura do período eleitoral. Ele é um espaço de opinião sobre algum tema do momento, a pessoa que escreve não necessita ser especialista naquele assunto, como acontece na coluna, mas o tema deve ser relevante. A partir dos formatos, podemos afirmar que a cobertura da Gazeta do Povo e do Diário dos Campos tende a ser semelhante, o que acontece também entre os jornais Folha de Londrina, Diário do Norte e Jornal da Manhã.

Depois de observar o formato das entradas, é importante atentar para o espaço que as notícias ocuparam. Isso revela quão importante os editores consideram certos temas. Na página dos impressos, cada lugar adquire um valor e uma importância diferenciada, o que significa que nenhuma notícia é diagramada de forma aleatória. Se a reportagem ocupar a página inteira, ela é considerada de grande relevância social para os editores, já se for apenas uma nota no canto inferior esquerdo, sua relevância é tida como baixa.

A tabela acima demonstra que as matérias ocuparam principalmente o quadrante superior direito e o quadrante superior esquerdo, que, somados, contabilizam mais de $50 \%$ dos espaços. Elas foram consideradas relevantes ao ocuparem a primeira dobra da página do jornal, porque há maior tendência de o público ler e olhar as fotografias e os infográficos dispostos na parte superior da página para depois, então, ler as notícias que vêm abaixo. Além disso, na primeira página, a metade superior da folha é aquela que fica exposta nas bancas de jornais e, por isso, é chamada de "vitrine do jornal". 
Tabela 2 - Localização das notícias nas páginas dos jornais

\begin{tabular}{|l|l|l|l|l|l|l|}
\hline Indicadores & $\begin{array}{l}\text { Diário do } \\
\text { Norte }\end{array}$ & $\begin{array}{l}\text { Folha de } \\
\text { Londrina }\end{array}$ & $\begin{array}{l}\text { Diário dos } \\
\text { Campos }\end{array}$ & $\begin{array}{l}\text { Jornal da } \\
\text { Manhã }\end{array}$ & $\begin{array}{l}\text { Gazeta do } \\
\text { Povo }\end{array}$ & Total \\
\hline Página Inteira & 4 & 9 & 3 & 7 & 8 & 31 \\
\hline $\begin{array}{l}\text { Metade } \\
\text { Superior }\end{array}$ & 20 & 8 & 34 & 36 & 20 & 118 \\
\hline $\begin{array}{l}\text { Metade } \\
\text { Inferior }\end{array}$ & 11 & 6 & 26 & 8 & 13 & 64 \\
\hline $\begin{array}{l}\text { Quadrante } \\
\text { Superior } \\
\text { Direito }\end{array}$ & 42 & 13 & 175 & 154 & 125 & 509 \\
\hline $\begin{array}{l}\text { Quadrante } \\
\text { Superior } \\
\text { Esquerdo }\end{array}$ & 37 & 52 & 74 & 98 & 201 & 462 \\
\hline $\begin{array}{l}\text { Quadrante } \\
\text { Inferior } \\
\text { Direito }\end{array}$ & 19 & 24 & 91 & 93 & 118 & 345 \\
\hline $\begin{array}{l}\text { Quadrante } \\
\text { Inferior } \\
\text { Esquerdo }\end{array}$ & 29 & 26 & 36 & 61 & 189 & 341 \\
\hline Total & 162 & 138 & 439 & 457 & 679 & 1875 \\
\hline
\end{tabular}

Fonte: Grupo de Pesquisa “Mídia, Política e Atores Sociais” (UEPG).

A tematização dos candidatos estava presente em notícias de grande destaque e visibilidade, pois houve matérias que ocuparam a página inteira do jornal, como foi o caso das 31 coletadas ou aproximadamente $2 \%$ da cobertura, o que torna o tema relevante.

Com relação ao tema das matérias, o que mais apareceu durante a cobertura - quando os candidatos estavam presentes - foi Campanha Eleitoral (88,06\%). Isso prova que os jornais veiculam notícias que têm relação com a atualidade e com os períodos nas quais estão inseridas, no caso, o período eleitoral, demonstrando, assim, que todos os jornais deram atenção especial à campanha eleitoral.

\section{Tabela 3 - Temática das entradas}

\begin{tabular}{|l|l|l|l|l|l|l|}
\hline TEMA & $\begin{array}{l}\text { Diário do } \\
\text { Norte }\end{array}$ & $\begin{array}{l}\text { Folha de } \\
\text { Londrina }\end{array}$ & $\begin{array}{l}\text { Diário dos } \\
\text { Campos }\end{array}$ & $\begin{array}{l}\text { Jornal da } \\
\text { Manhã }\end{array}$ & $\begin{array}{l}\text { Gazeta } \\
\text { do Povo }\end{array}$ & Total \\
\hline Campanha eleitoral & 127 & 122 & 406 & 449 & 585 & 1689 \\
\hline Político-institucional & 7 & 10 & 17 & 21 & 71 & 126 \\
\hline Economia & 0 & 0 & 5 & 1 & 1 & 7 \\
\hline Política social & 5 & 2 & 1 & 4 & 12 & 24 \\
\hline Infraestrutura e meio ambiente & 19 & 0 & 3 & 3 & 0 & 25 \\
\hline Violência e segurança & 1 & 1 & 0 & 0 & 4 & 6 \\
\hline Ético-moral & 2 & 9 & 0 & 3 & 0 & 14 \\
\hline Política para esporte & 0 & 0 & 2 & 0 & 1 & 3 \\
\hline Cultura e variedades & 0 & 0 & 3 & 4 & 0 & 7 \\
\hline $\begin{array}{l}\text { Política estadual, nacional, } \\
\text { internacional }\end{array}$ & 0 & 0 & 1 & 0 & 0 & 1 \\
\hline Outros & 1 & 0 & 7 & 3 & 5 & 16 \\
\hline Total & 162 & 144 & 445 & 488 & 679 & 1918 \\
\hline
\end{tabular}

Fonte: Grupo de Pesquisa “Mídia, Política e Atores Sociais” (UEPG). 
Percebe-se, a partir da análise da localização das notícias nas páginas dos jornais e dos formatos, que os impressos têm apresentado as mesmas tendências e padrões de cobertura. Quanto aos temas abordados pelos jornais, também houve um equilíbrio na cobertura, visto que, nos cinco periódicos, o tema que mais apareceu foi Campanha Eleitoral; em segundo lugar, Político-Institucional, exceto no Diário do Norte, que deu visibilidade para Infraestrutura e Meio Ambiente. Se compararmos a quantidade de vezes que o segundo tema apareceu à quantidade de vezes que Campanha Eleitoral esteve presente, podemos perceber que sua porcentagem é irrisória, mas nem por isso o tema deixa de ser importante.

Assuntos importantes para o debate público e para a formação da opinião pública acerca de melhores propostas de políticas públicas dos candidatos foram pouco abordados nos jornais paranaenses estudados, visto que Políticas Sociais, Infraestrutura e Meio Ambiente, e Violência representaram apenas $2,8 \%$ de toda a cobertura.

A fim de detalhar as temáticas e torná-las inteligíveis, subdividimos os temas com suas especificidades. Dentro da temática Campanha Eleitoral estão Corrida Eleitoral, Campanha para Prefeito e para Vereador, por exemplo. Assim também foi feito com os demais temas gerais.

O Diário dos Campos, Jornal da Manhã e Gazeta do Povo deram maior cobertura às campanhas dos candidatos a prefeitos que os jornais de Londrina e Maringá. O número de aparições de notícias relacionadas à campanha em Ponta Grossa foi três vezes maior do que as apresentadas no Diário do Norte e na Folha de Londrina, já em Curitiba esse número foi quatro vezes maior.

\section{Tabela 4 - Detalhamento dos temas}

\begin{tabular}{|c|c|c|c|c|c|c|}
\hline Tema Específico & $\begin{array}{l}\text { Diário } \\
\text { do Norte }\end{array}$ & $\begin{array}{l}\text { Folha de } \\
\text { Londrina }\end{array}$ & $\begin{array}{l}\text { Diário dos } \\
\text { Campos }\end{array}$ & $\begin{array}{l}\text { Jornal da } \\
\text { Manhã }\end{array}$ & $\begin{array}{l}\text { Gazeta } \\
\text { do Povo }\end{array}$ & Total \\
\hline Corrida eleitoral & 4 & 2 & 40 & 13 & 40 & 99 \\
\hline Campanha para prefeito & 123 & 118 & 361 & 436 & 542 & 1580 \\
\hline Campanha para vereador & 0 & 2 & 5 & 0 & 3 & 10 \\
\hline Governo do Estado & 0 & 0 & 4 & 0 & 14 & 18 \\
\hline Governo Municipal & 3 & 0 & 8 & 18 & 40 & 69 \\
\hline Governo Federal & 0 & 0 & 2 & 0 & 2 & 4 \\
\hline Câmara Federal e Senado & 0 & 0 & 0 & 0 & 1 & 1 \\
\hline Assembleia Estadual & 1 & 0 & 2 & 1 & 3 & 7 \\
\hline Poder Judiciário Geral & 2 & 9 & 0 & 0 & 5 & 16 \\
\hline Justiça Eleitoral & 1 & 1 & 1 & 1 & 2 & 6 \\
\hline Partido ou instituições políticas & 0 & 0 & 0 & 1 & 4 & 5 \\
\hline Finanças & 0 & 0 & 2 & 0 & 0 & 2 \\
\hline Indústria & 0 & 0 & 1 & 0 & 0 & 1 \\
\hline Comércio & 0 & 0 & 1 & 0 & 0 & 1 \\
\hline Política Econômica & 0 & 0 & 0 & 1 & 1 & 2 \\
\hline Educação & 0 & 2 & 0 & 0 & 1 & 3 \\
\hline Saúde & 3 & 0 & 1 & 1 & 8 & 13 \\
\hline Habitação & 0 & 0 & 0 & 0 & 1 & 1 \\
\hline Políticas Compensatórias & 0 & 0 & 1 & 1 & 1 & 3 \\
\hline Minorias: Juventude & 0 & 0 & 0 & 2 & 0 & 2 \\
\hline Minorias: Terceira Idade & 0 & 0 & 0 & 0 & 1 & 1 \\
\hline Assistencialismo & 2 & 0 & 0 & 0 & 0 & 2 \\
\hline Obras & 0 & 0 & 1 & 1 & 0 & 2 \\
\hline Saneamento básico & 0 & 0 & 0 & 1 & 0 & 1 \\
\hline Transporte e infraestrutura urbana & 8 & 0 & 0 & 1 & 0 & 9 \\
\hline Questões ambientais e ecológicas & 11 & 0 & 2 & 0 & 0 & 13 \\
\hline Violência e crime organizado & 1 & 1 & 0 & 0 & 0 & 2 \\
\hline Política de segurança & 0 & 0 & 0 & 0 & 4 & 4 \\
\hline Corrupção & 2 & 9 & 0 & 3 & 0 & 14 \\
\hline Espaços culturais & 0 & 0 & 2 & 0 & 0 & 2 \\
\hline Eventos esportivos & 0 & 0 & 0 & 0 & 1 & 1 \\
\hline Política de incentivo ao turismo & 0 & 0 & 1 & 4 & 0 & 5 \\
\hline Outros & 1 & 0 & 7 & 3 & 5 & 16 \\
\hline Total & 162 & 144 & 445 & 488 & 679 & 1918 \\
\hline
\end{tabular}

Fonte: Grupo de Pesquisa “Mídia, Política e Atores Sociais” (UEPG). 
Nos cinco jornais estudados, o tema específico que mais apareceu foi Campanha para prefeito, contendo um total de 1.580 aparições ou $82,377 \%$. Isso mostra que a abrangência do jornal corresponde ao local de circulação do mesmo, pois os quatro jornais de cunho local apresentaram notícias para a população local, sendo que a Gazeta do Povo, que é um jornal regional, também trouxe notícias sobre o candidato a prefeito de sua cidade. No Jornal da Manhã o tema governo municipal também apareceu $(1,45 \%)$, mas em proporções bem menores em comparação com a campanha para prefeito. Já no seu concorrente, o segundo tema específico mais visível foi a corrida eleitoral, com 3,22\%. O Diário dos Campos preocupou-se, em segunda instância, em apresentar as mudanças e resultados das pesquisas de opinião sobre a campanha. Já o Diário do Norte deu atenção secundária para as questões ambientais e a Folha de Londrina não teve um tema que apareceu mais que os outros, pois tanto notícias sobre o poder judiciário geral e a corrupção e a má gestão do dinheiro público obtiveram $0,7 \%$ de aparições. $A$ Gazeta do Povo deu atenção secundária à corrida eleitoral e ao governo municipal de Curitiba, com 5,89\% do total de sua cobertura. Logo, percebe-se que os jornalistas, quando citavam os principais candidatos ao governo de suas cidades (Maringá, Londrina, Ponta Grossa e Curitiba), tenderam a relacioná-los diretamente com a campanha eleitoral, com a Corrida Eleitoral e com o Governo Municipal.

Esse resultado já era esperado, pois segundo os critérios de noticiabilidade, as notícias devem ser atuais, relevantes, de interesse público e abranger o maior número de pessoas possíveis. Como as eleições para prefeitos e vereadores do Paraná encaixam-se nesses critérios, elas facilmente entram na cobertura jornalística do período de agosto, setembro e outubro - que é quando começam as discussões sobre as eleições e os candidatos iniciam campanha.

Observou-se também o enquadramento que as reportagens receberam para saber qual é o tratamento e o direcionamento que os jornais deram às grandes notícias relacionadas à política e campanha eleitoral. A tabela abaixo (cinco) mostra a classificação das reportagens segundo os quatro tipos de enquadramento (Porto, 2004).

O primeiro enquadramento trata a disputa eleitoral como uma corrida entre os candidatos, assim, a ênfase é dada para o candidato que está na frente, avançando ou que está ficando para trás nos resultados das pesquisas. Já no segundo é enfatizada a vida dos candidatos, mais do que os aspectos amplos institucionais e os que dizem respeito à política. $O$ foco da cobertura das reportagens nesse framing é o indivíduo e a sua vida pessoal.

O enquadramento temático, por sua vez, é que mais interessa para este trabalho. Por meio dele, se dá mais atenção aos padrões interpretativos que enfatizam as posições e as propostas dos candidatos. "A ênfase das notícias que adotam este ponto de vista está nas plataformas e programas representados pelos diferentes candidatos" (PORTO, 2004, p. 13). O último é o episódico e se refere às reportagens descritivas, não interpretativas, que estão centradas em descrever os fatos ou as declarações dos candidatos, sem o enfoque característico dos três enquadramentos anteriores.

Observar o enquadramento é importante, pois, como explica Porto, "ao produzir o noticiário, jornalistas se baseiam em discursos que estão presentes na esfera pública, mas também contribuem com seus próprios enquadramentos, dando formas aos 'pacotes interpretativos' que fazem parte de qualquer cultura" (2000, p. 12). 
Tabela 5 - Enquadramento das reportagens

\begin{tabular}{|l|l|l|l|l|l|}
\hline Enquadramento & Corrida de Cavalos & Personalista & Temático & Episódico & Total \\
\hline Diário do Norte & 9 & 6 & 20 & 41 & 76 \\
\hline Folha de Londrina & 9 & 13 & 16 & 75 & 113 \\
\hline Diário dos Campos & 29 & 8 & 25 & 99 & 161 \\
\hline Jornal da Manhã & 32 & 7 & 30 & 139 & 208 \\
\hline Gazeta do Povo & 16 & 21 & 77 & 128 & 242 \\
\hline Total & 95 & 55 & 168 & 482 & 800 \\
\hline
\end{tabular}

Fonte: Grupo de Pesquisa “Mídia, Política e Atores Sociais” (UEPG).

Como era de se esperar, o enquadramento episódico foi aquele que teve mais presença nas reportagens publicadas pelos cinco jornais. A rotina de produção da notícia é ágil e requer rapidez dos jornalistas faz com que as reportagens transmitidas por eles sejam mais descritivas do que analíticas. Mas, isso não significa também que o repórter está proibido de interpretar os fatos. Do total de 800 reportagens produzidas nesse período, 482 representaram o enquadramento episódico, ou seja, 60,25\% delas foram descrições do andamento das campanhas dos candidatos a prefeitos.

Os jornais também trouxeram reportagens interpretativas, porém em menor escala. No geral, as reportagens analíticas aparecem em segundo lugar em número de utilizações, somando-se $21 \%$ do total. Tanto o Diário dos Campos como o Jornal da Manhã utilizaram mais vezes a corrida de cavalos à interpretação dos dados. Isso porque, de 208 reportagens que o Jornal da Manhã apresentou e das 161 que o Diário dos campos publicou, respectivamente 32 (15,38\%) e $29(18,01 \%)$ delas foram sobre o andamento das pesquisas de opinião.

Dentre os quatro impressos do interior, o que mais apresentou reportagens foi o Jornal da Manhã, com 208 no total, demonstrando, dessa forma, uma preocupação maior em trazer dados e complementos às notícias para que o leitor melhor compreenda e assimile o conteúdo discutido pelo veículo. A Gazeta do Povo veiculou 242 reportagens durante os três meses, sendo dos cinco o jornal que mais utilizou esse formato jornalístico, o que aponta uma preocupação em aprofundar a discussão sobre a campanha eleitoral bem como sobre as mudanças e os avanços dos candidatos à prefeitura de Curitiba.

O Diário do Norte foi o que menos produziu e veiculou reportagens sobre o período eleitoral e sobre os candidatos à prefeitura de Maringá, pois das 558 reportagens classificadas na pesquisa, apenas 76 foram publicadas no referido período. São através desses dados que se pode indicar o posicionamento e a linha editorial dos jornais observados. Enquanto o Jornal da Manhã, de Ponta Grossa, deu atenção mais destacada à campanha eleitoral para prefeito $(37,07 \%)$, o Diário do Norte não trouxe mais que $15 \%$ do total, o que demonstra que a linha editorial do primeiro enfatiza mais a cobertura política em comparação ao segundo citado $(D N)$.

A partir do enquadramento é possível perceber a linha editorial que os jornais seguem, haja vista que são os editores que selecionam as temáticas a serem publicadas, no entanto são os repórteres que interpretam e transcrevem os fatos. Além de perceber a linha editorial, é possível levantar o tratamento que os jornalistas dão às notícias, ora interpretando-as ora apenas descrevendo os fatos. Por isso, essa pesquisa cruzou dados do enquadramento dado às reportagens e os atores que nelas estavam envolvidos.

Na tabela abaixo, o principal candidato ao cargo de prefeito de Ponta Grossa - Pedro Wosgrau Filho (PSDB) -, quando apareceu em notícias que falavam sobre a campanha eleitoral, 
cerca de $60 \%$ delas foram apenas descritivas, e aproximadamente $13 \%$ receberam maior atenção dos jornalistas com o uso da interpretação dos dados contidos na reportagem.

Tabela 6 - Enquadramento no Diário dos Campos e atores políticos

\begin{tabular}{|c|c|c|c|c|c|c|}
\hline \multicolumn{3}{|c|}{ Indicadores } & \multicolumn{4}{|l|}{ Temas } \\
\hline \multirow{12}{*}{ 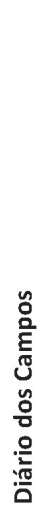 } & \multirow[b]{6}{*}{$-\ldots$} & Enquadramentos & $\begin{array}{l}\text { Campanha } \\
\text { Eleitoral }\end{array}$ & $\begin{array}{l}\text { Político } \\
\text { Institucional }\end{array}$ & Economia & $\begin{array}{l}\text { Cultura e } \\
\text { Variedades }\end{array}$ \\
\hline & & Corrida de Cavalos & $28(23,9 \%)$ & 0 & 0 & 0 \\
\hline & & Personalista & $4(3,4 \%)$ & 0 & 0 & 0 \\
\hline & & Temático & $15(12,8 \%)$ & $1(50 \%)$ & $1(100 \%)$ & 0 \\
\hline & & Episódico & $70(59,8 \%)$ & $1(50 \%)$ & 0 & $1(100 \%)$ \\
\hline & & Total & $117(100 \%)$ & $2(100 \%)$ & $1(100 \%)$ & $1(100 \%)$ \\
\hline & \multirow{6}{*}{ 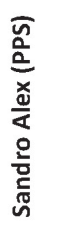 } & & & & & \\
\hline & & Corrida de Cavalos & $26(23,2 \%)$ & 0 & 0 & 0 \\
\hline & & Personalista & $3(2,7 \%)$ & 0 & 0 & 0 \\
\hline & & Temático & $17(15,2 \%)$ & $1(100 \%)$ & $1(100 \%)$ & 0 \\
\hline & & Episódico & $66(58,9 \%)$ & 0 & 0 & 0 \\
\hline & & Total & $112(100 \%)$ & $1(100 \%)$ & $1(100 \%)$ & 0 \\
\hline
\end{tabular}

Fonte: Grupo de Pesquisa “Mídia, Política e Atores Sociais” (UEPG).

Já seu concorrente - Sandro Alex (PPS) -, quando estava presente nas reportagens sobre a campanha, recebeu atenção especial na apuração em mais de $15 \%$ das matérias. Porém, assim como Wosgrau, a presença maciça esteve nas reportagens apenas descritivas (quase $60 \%$ ). Percebe-se que os índices relacionados ao tema 'campanha eleitoral' e os demais índices são quase os mesmos para ambos os candidatos, o que mostra que o Diário dos Campos não reforçou mais a notícia para um candidato do que para outro.

A tabela a seguir (7) mostra a relação das reportagens e seus enquadramentos cruzados com os dois principais candidatos de Ponta Grossa, porém com a diferença que o jornal em questão é o Jornal da Manhã. Neste jornal, a relação é parecida com a cobertura que o Diário dos Campos fez durante os três meses. Quando Wosgrau foi citado nas reportagens sobre Campanha Eleitoral, a cobertura dada foi na maioria das vezes apenas descritiva (66\%). Do mesmo modo, quando Sandro Alex esteve presente nas reportagens do mesmo tema, $65 \%$ das vezes a notícia era apenas descritiva.

Tabela 7 - Enquadramentos no Jornal da Manhã e Atores Políticos

\begin{tabular}{|c|c|c|c|c|c|c|}
\hline \multicolumn{3}{|c|}{ Indicadores } & \multicolumn{4}{|l|}{ Temas } \\
\hline \multirow{12}{*}{$\begin{array}{l}\frac{3 \pi}{\frac{\pi}{c}} \\
\frac{5}{\pi} \\
\frac{\pi}{\pi} \\
\frac{\pi}{0} \\
\frac{\pi}{5} \\
\frac{5}{5}\end{array}$} & \multirow{6}{*}{ 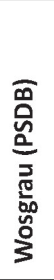 } & Enquadramentos & $\begin{array}{l}\text { Campanha } \\
\text { Eleitoral }\end{array}$ & $\begin{array}{l}\text { Político } \\
\text { Institucional }\end{array}$ & $\begin{array}{l}\text { Política } \\
\text { Social }\end{array}$ & $\begin{array}{l}\text { Infraestrutura e } \\
\text { meio ambiente }\end{array}$ \\
\hline & & Corrida de Cavalos & $30(21,1 \%)$ & 0 & 0 & 0 \\
\hline & & Personalista & $4(2,8 \%)$ & 0 & 0 & 0 \\
\hline & & Temático & $14(9,9 \%)$ & 0 & 0 & $2(100 \%)$ \\
\hline & & Episódico & $94(66,2 \%)$ & $5(100 \%)$ & $1(100 \%)$ & 0 \\
\hline & & Total & $142(100 \%)$ & $5(100 \%)$ & $1(100 \%)$ & $2(100 \%)$ \\
\hline & \multirow{6}{*}{ 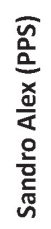 } & & & & & \\
\hline & & Corrida de Cavalos & $27(21,4 \%)$ & 0 & 0 & 0 \\
\hline & & Personalista & $2(1,6 \%)$ & 0 & 0 & 0 \\
\hline & & Temático & $14(11,1 \%)$ & 0 & 0 & $1(100 \%)$ \\
\hline & & Episódico & $83(65,9 \%)$ & $2(100 \%)$ & $1(100 \%)$ & 0 \\
\hline & & Total & $126(100 \%)$ & $2(100 \%)$ & $1(100 \%)$ & $1(100 \%)$ \\
\hline
\end{tabular}

Pesquisa “Mídia, Política e Atores Sociais” (UEPG). 
A maior diferença entre este jornal e o anterior está nos temas das reportagens, pois no Jornal da Manhã foi publicada uma reportagem sobre políticas sociais que relacionou os dois principais candidatos de característica descritiva e outras duas matérias sobre a infraestrutura e meio ambiente, que trouxeram uma análise mais crítica, quando Wosgrau (PSDB) e Sandro Alex (PPS) tiveram visibilidade.

Contudo, como se observou nas duas tabelas, em Ponta Grossa não houve muitas diferenças na cobertura das matérias que envolveram os principais candidatos a prefeito do município, sendo que Pedro Wosgrau Filho concorria à reeleição no município e, por isso, poderia haver mais notícias relacionadas a ele, sem que o jornal estivesse sendo tendencioso. Isso mostra que houve uma 'neutralidade' por parte dos jornais em não tender mais para um político (dando a ele mais espaço de crítica) do que para o outro.

\section{Tabela 8 - Enquadramentos na Folha de Londrina e Atores Políticos}

\begin{tabular}{|c|c|c|c|c|c|c|}
\hline \multicolumn{3}{|c|}{ Indicadores } & \multicolumn{4}{|l|}{ Temas } \\
\hline \multirow{12}{*}{ 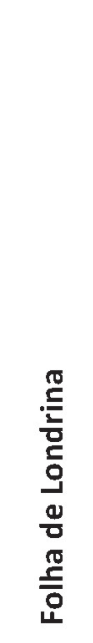 } & \multirow{6}{*}{ 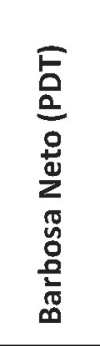 } & Enquadramentos & $\begin{array}{l}\text { Campanha } \\
\text { Eleitoral }\end{array}$ & $\begin{array}{l}\text { Político } \\
\text { Institucional }\end{array}$ & $\begin{array}{l}\text { Violência e } \\
\text { Segurança }\end{array}$ & Ético e Moral \\
\hline & & Corrida de Cavalos & $7(13,7 \%)$ & 0 & 0 & 0 \\
\hline & & Personalista & $3(5,9 \%)$ & $7(100 \%)$ & 0 & 0 \\
\hline & & Temático & $11(21,6 \%)$ & 0 & 0 & $1(33,3 \%)$ \\
\hline & & Episódico & $30(58,8 \%)$ & 0 & $1(100 \%)$ & $2(66,7 \%)$ \\
\hline & & Total & $51(100 \%)$ & $7(100 \%)$ & $1(100 \%)$ & $3(100 \%)$ \\
\hline & \multirow{6}{*}{ 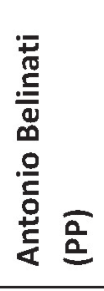 } & & & & & \\
\hline & & Corrida de Cavalos & $9(12 \%)$ & 0 & 0 & 0 \\
\hline & & Personalista & $3(4 \%)$ & 0 & 0 & 0 \\
\hline & & Temático & $10(13,3 \%)$ & 0 & 0 & $1(14,3 \%)$ \\
\hline & & Episódico & $53(70,7 \%)$ & $1(100 \%)$ & 0 & $6(85,7 \%)$ \\
\hline & & Total & $75(100 \%)$ & $1(100 \%)$ & 0 & $7(100 \%)$ \\
\hline
\end{tabular}

Fonte: Grupo de Pesquisa “Mídia, Política e Atores Sociais” (UEPG).

Já no jornal de Londrina - Folha de Londrina -, quando o candidato Barbosa Neto (PDT) estava presente em reportagens, elas tenderam a ser mais descritivas, assim como aconteceu com os candidatos de Ponta Grossa. Cerca de $60 \%$ das reportagens sobre Campanha Eleitoral eram descritivas. Algo interessante para se perceber é que diferente dos candidatos anteriores, os concorrentes Barbosa Neto (PDT) e Antonio Belinati (PP) foram relacionados ao tema Ético e moral. Isso significa que os dois estavam presentes em reportagens sobre desvio ou má gestão do dinheiro público e corrupção. Das três reportagens que Barbosa Neto estava presente, duas foram descritivas e uma mais aprofundada e com maior crítica sobre o tema. Já Antonio Belinati apareceu duas vezes mais em reportagens sobre corrupção do que seu concorrente, mas em apenas uma reportagem a crítica foi mais profunda, porque seis delas foram enquadradas como Episódicas. Barbosa Neto ainda estava presente no tema Violência e Segurança, o que não aconteceu com Antonio Belinati. Quando o tema versava sobre a Política Institucional, Barbosa Neto esteve relacionado à sua opinião, seu comportamento, enfim ao seu perfil, diferente de Antonio Belinati que só apareceu uma vez em reportagem descritiva e não personalista. Na Folha de Londrina percebem-se algumas diferenças de enquadramento temático dependendo de qual candidato a prefeito se fala, como é o caso das reportagens sobre política institucional que 
exploraram mais o comportamento e a opinião de Barbosa Neto bem como as reportagens sobre corrupção, que mostraram de forma descritiva mais Belinati do que seu concorrente.

Tabela 9 - Enquadramentos no Diário do Norte e Atores Políticos

\begin{tabular}{|c|c|c|c|c|c|c|c|}
\hline \multicolumn{3}{|c|}{ Indicadores } & \multicolumn{5}{|l|}{ Temas } \\
\hline \multirow{11}{*}{ 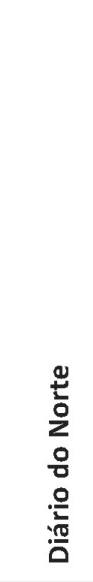 } & \multirow{6}{*}{ 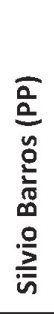 } & Enquadramentos & $\begin{array}{l}\text { Campanha } \\
\text { Eleitoral }\end{array}$ & $\begin{array}{l}\text { Político } \\
\text { Institucional }\end{array}$ & $\begin{array}{l}\text { Política } \\
\text { Social }\end{array}$ & $\begin{array}{l}\text { Infraestrutura e } \\
\text { meio ambiente }\end{array}$ & $\begin{array}{l}\text { Outros } \\
\text { Temas }\end{array}$ \\
\hline & & Corrida de Cavalos & $2(7,7 \%)$ & 0 & 0 & 0 & 0 \\
\hline & & Personalista & $1(3,8 \%)$ & $2(66,7 \%)$ & 0 & 0 & 0 \\
\hline & & Temático & $4(15,4 \%)$ & 0 & $1(100 \%)$ & $1(100 \%)$ & 0 \\
\hline & & Episódico & $19(73,1 \%)$ & $1(33,3 \%)$ & 0 & 0 & 0 \\
\hline & & Total & $26(100 \%)$ & $3(100 \%)$ & $1(100 \%)$ & $1(100 \%)$ & 0 \\
\hline & \multirow{5}{*}{ 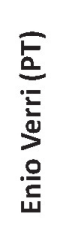 } & Corrida de Cavalos & $5(11,6 \%)$ & 0 & 0 & 0 & 0 \\
\hline & & Personalista & $1(2,3 \%)$ & 0 & 0 & 0 & $1(100 \%)$ \\
\hline & & Temático & $10(23,3 \%)$ & $1(33,3 \%)$ & $1(100 \%)$ & $1(100 \%)$ & 0 \\
\hline & & Episódico & $27(62,8 \%)$ & $2(66,7 \%)$ & 0 & 0 & 0 \\
\hline & & Total & $43(100 \%)$ & $3(100 \%)$ & $1(100 \%)$ & $1(100 \%)$ & $1(100 \%)$ \\
\hline
\end{tabular}

Fonte: Grupo de Pesquisa “Mídia, Política e Atores Sociais” (UEPG).

O jornal de Maringá - Diário do Norte -, diferentemente do Diário dos Campos e da Folha de Londrina, trouxe o tema Política Social quando falou sobre os dois candidatos a prefeito do município, sendo que em ambos o enquadramento utilizado foi o temático. Isso significa que, mesmo reportando apenas uma vez o tema para cada candidato, a cobertura foi neutra, porque deu o mesmo detalhamento de dados e explicação para os dois candidatos. O mesmo aconteceu com o tema Infraestrutura Urbana e Meio Ambiente. Quando Silvio Barros (PP) estava presente nas reportagens sobre Política Institucional, foi dado enfoque a sua personalidade e opinião $(66,7 \%)$, já para Enio Verri (PT) a cobertura jornalística foi mais descritiva e com menos opinião do candidato, haja vista que deram ênfase ao enquadramento Episódico (66,7\%).

Com relação às reportagens sobre o tema Campanha Eleitoral, Enio Verri apareceu quase que o dobro de vezes que Silvio Barros, ou seja, estava em apenas 43 reportagens em detrimento das apenas 26 em que aparecia o outro. Os jornalistas tenderam a utilizar mais o aprofundamento das notícias, fatos e dados quando Verri estava presente nas notícias, porque foram publicadas 10 reportagens $(23,3 \%)$ com enquadramento temático. Já Silvio Barros teve visibilidade em quatro reportagens $(15,4 \%)$ do enquadramento acima citado, sendo que Barros era candidato à reeleição do cargo.

A cobertura do jornal de Maringá tendeu a dar maior espaço de debate e visibilidade para Enio Verri quando falou sobre a Campanha Eleitoral, porque ele esteve presente mais vezes em reportagens aprofundadas do que seu concorrente ao governo. Porém, em se tratando do tema Política Social e Infraestrutura Urbana e Meio Ambiente, houve um equilíbrio nas abordagens. 
Tabela 10 - Enquadramentos na Gazeta do Povo e Atores Políticos

\begin{tabular}{|c|c|c|c|c|c|}
\hline \multicolumn{3}{|c|}{ Indicadores } & \multicolumn{3}{|l|}{ Temas } \\
\hline \multirow{11}{*}{ 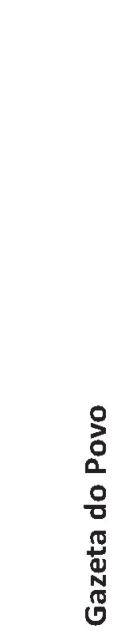 } & \multirow{6}{*}{ 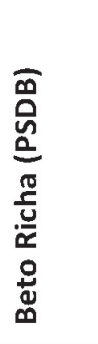 } & Enquadramentos & Campanha Eleitoral & $\begin{array}{l}\text { Político } \\
\text { Institucional }\end{array}$ & $\begin{array}{l}\text { Política } \\
\text { Social }\end{array}$ \\
\hline & & Corrida de Cavalos & $13(10,7 \%)$ & 0 & 0 \\
\hline & & Personalista & $8(6,6 \%)$ & 0 & 0 \\
\hline & & Temático & $36(29,8 \%)$ & $14(48,3 \%)$ & $2(100 \%)$ \\
\hline & & Episódico & $64(52,9 \%)$ & $15(51,7 \%)$ & 0 \\
\hline & & Total & $121(100 \%)$ & $29(100 \%)$ & $2(100 \%)$ \\
\hline & \multirow{5}{*}{ 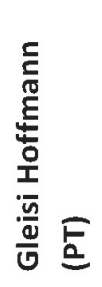 } & Corrida de Cavalos & $12(12,6 \%)$ & 0 & 0 \\
\hline & & Personalista & $3(3,2 \%)$ & 0 & 0 \\
\hline & & Temático & $29(30,5 \%)$ & $1(50 \%)$ & $2(100 \%)$ \\
\hline & & Episódico & $51(53,7 \%)$ & $1(50 \%)$ & 0 \\
\hline & & Total & $95(100 \%)$ & $2(100 \%)$ & $2(100 \%)$ \\
\hline
\end{tabular}

Fonte: Grupo de Pesquisa “Mídia, Política e Atores Sociais” (UEPG).

A Gazeta do Povo, quando falou sobre as Políticas Sociais, também equilibrou sua abordagem para os dois candidatos à Prefeitura de Curitiba, porque trouxe tanto Beto Richa (PSDB) quanto Gleisi Hoffmann (PT) em duas reportagens temáticas, ou seja, em reportagens mais críticas e aprofundadas e com maior quantidade de dados e informações. Isso é importante porque são através de análises mais aprofundadas que as pessoas têm condições de debater e formar sua opinião.

Mas, em contrapartida, o jornal deu maior visibilidade para Beto Richa do que para Gleisi Hoffmann quando falou sobre Política Institucional, haja vista que enquanto ele apareceu em 29 reportagens sobre o tema, ela esteve presente em apenas duas. Uma reposta para tal diferença pode estar relacionada ao fato que Beto Richa era candidato à reeleição e, portanto, estava mais relacionado aos temas da política da cidade do que a candidata, pois era prefeito da capital. Quanto ao tema Campanha Eleitoral ele também teve maior visibilidade que Gleisi Hoffmann, porque apareceu 26 vezes a mais que ela. Quanto à distribuição dos enquadramentos das reportagens sobre a campanha, pode-se dizer que estava equilibrada, porque ambos aparecem mais de $50 \%$ das vezes em reportagens descritivas, cerca de $30 \%$ em reportagens em profundidade, pouco mais de $10 \%$ em reportagens sobre as pesquisas de opinião, retrocessos e avanços na campanha; ele figurou em $6,6 \%$ em reportagens sobre sua personalidade enquanto ela em $3,2 \%$ deu sua opinião e falou sobre si.

Com a análise dos enquadramentos relacionados aos temas das reportagens veiculadas na Gazeta do Povo, podemos afirmar que Beto Richa teve mais espaço de visibilidade importante do que Gleisi Hoffmann, porque ele apareceu no jornal mais vezes que ela e teve uma cobertura mais aprofundada sobre sua Campanha Eleitoral. Já quando o tema foi Política Social os dois candidatos apareceram da mesma maneira. Assim, nota-se que é importante verificar como os jornais dão visibilidade para os temas e candidatos, porque muitas vezes a quantidade de aparições nas páginas dos jornais é a mesma, mas a forma de tratamento da notícia é diferente. 


\section{CONSIDERAÇÕES FINAIS}

Os jornais demonstraram grande similaridade na cobertura do período eleitoral, apesar de não estarem localizados nas mesmas cidades e terem como proprietários diferentes grupos de comunicação. Os cinco jornais analisados apresentaram o mesmo padrão na cobertura jornalística dos candidatos a prefeito dos municípios e das eleições, em geral, como se pode comprovar através da quantidade de notícias dedicadas ao tema, do formato utilizado para publicar as matérias, dos enquadramentos das reportagens e do posicionamento do tema nas páginas dos jornais.

É importante perceber que a mídia direcionou o debate público principalmente para o tema Campanha Eleitoral, deixando fora da pauta outros assuntos, como, por exemplo, a apresentação de políticas públicas e ações relacionadas à saúde, educação e infraestrutura - todos poderiam ter sido vinculados à disputa eleitoral nos municípios pela cobertura, o que nos permite afirmar que a cobertura jornalística das principais cidades paranaenses, durante o período eleitoral, foi fundamentalmente uma descrição da campanha dos candidatos a prefeito dos municípios estudados e acompanharam os índices das pesquisas de opinião a respeito dos mesmos. Mesmo quando os jornalistas utilizaram o formato "Reportagem", esta abordagem foi apenas descritiva e pouco analítica. Tal prática, nem sempre, permite aos leitores terem subsídios necessários para gerar um debate mais aprofundado sobre as propostas e ações dos candidatos.

Porém, por outro lado, cabe lembrar que os jornais levaram em consideração o contexto no qual estavam inseridos, pois privilegiaram notícias relacionadas ao tema de destaque no momento, que, no caso, eram as eleições. Ao mesmo tempo, destacaram os candidatos de seus municípios demonstrando preocupação com seu público-alvo.

Em função de o jornal ser entendido como o meio de comunicação que pode aprofundar as notícias e trazer mais informações do que os demais veículos de comunicação, a pesquisa demonstra que ficou faltando em suas páginas informações referentes ao debate de políticas públicas sociais, o que gera uma perda de informação para os leitores. Portanto, mesmo sabendo que a campanha eleitoral para prefeitos teve grande espaço na mídia, percebe-se que temas de relevância social foram silenciados pelos jornalistas, o que levou, consequentemente, a uma cobertura mais descritiva e menos analítica no caso dos veículos analisados aqui. A esses resultados espera-se que sejam agregadas pesquisas futuras que possam comparar o desempenho dos jornais nas coberturas eleitorais em outros municípios ou diferentes esferas de representação política.

\section{REFERÊNCIAS BIBLIOGRÁFICAS}

AMARAL, Luís. Jornalismo: matéria de primeira página. Rio de Janeiro: Tempo Brasileiro, 1978.

GALERA, Maria del Carmen García; CONDE, Maria Rosa Berganza. El método científico aplicado a la investigacion en Comunicacion mediática. In: CONDE, Maria Rosa Berganza; ROMÁN, José Ruiz San (coord.). Investigar en comunicación: guiá práctica de métodos y técnicas deinvestigación en comunicacíon. McGrawHill: Madrid, 2005.

HABERMAS, Jürgen. Mudança estrutural da esfera pública: investigações quanto a uma categoria da sociedade burguesa. 2. ed. Rio de Janeiro: Tempo Brasileiro, 2003.

Século XXI, UFSM, Santa Maria, v. 1, n. 2, p. 79-94, jul./dez. 2011 
KUNCZIK, Michael. Conceitos de jornalismo: Norte e Sul: Manual de comunicação. Traduzido por Rafael Varela Jr. 2. ed. 1ạ reimpr. São Paulo: Editora da Universidade de São Paulo, 2001.

McCOMBS, Maxwell. Building consensus: the news media's agenda-setting roles. University of Texas at Austin. Political Communication, v. 1, n. 4, p. 433-443, 1997.

NOËLLE-NEUMANN, Elisabeth. La espiral del silencio. Opinión pública: nuestra piel social. Barcelona, 1995. In: http://www.infoamerica.org/documentos_pdf/noelle-neumann.pdf, em 10 de abril de 2008.

PORTO, Mauro. A mídia brasileira e a eleição presidencial de 2000 nos EUA: A cobertura do Jornal Folha de S. Paulo. Artigo integrante do trabalho "Framing the 2000. U.S. presidential election: The coverage by the Brazilian media", apresentado 51a Conferência Anual da International Communication Association (ICA), Washington D.C., Estados Unidos, 25 a 28 de Maio de 2001.

SOUSA, Jorge Pedro. Teorias da notícia e do jornalismo. Chapecó: Argos, 2002.

TRAQUINA, Nelson. Porque as notícias são como são. 2. ed. Florianópolis: Insular, 2005.

WOLF, Mauro. Teorias da comunicação. Traduzido por Maria Jorge Vilar de Figueiredo. 9. ed. Lisboa: Presença, 2006.

Recebido em 14/04/2010

Aprovado em 30/08/2010 